\title{
A CHAT Approach of Light and Colors in Science Teaching for the Early Grades
}

\author{
Eleni Kolokouri ${ }^{1} \&$ Katerina Plakitsi ${ }^{1, *}$ \\ ${ }^{1}$ Department of Preschool Education, University of Ioannina,Greece \\ *Correspondence: Department of Preschool Education, University of Ioannina, Greece. Tel: 30-697-289-8463. E-mail: \\ kplakits@gmail.com
}

Received: April 4, 2016

Accepted: April 16, $2016 \quad$ Online Published: July 6, 2016

doi:10.5430/wje.v6n4p1

URL: http://dx.doi.org/10.5430/wje.v6n4p1

\begin{abstract}
This article describes a research study on the connection of Cultural Historical Activity Theory (CHAT) with Science Education in the early grades. The research study took place in the University of Ioannina, Greece with the support of the @fise research group. Within this frame, a narrative about light, colors and shadows was written as part of an Innovative Science Curriculum for the early grades. As a next step, the narrative was turned to a 20 minute animation in the scratch program and a series of science activities about light, colors and shadows were designed. The Science Curriculum was implemented in 4 pre-primary school classrooms. Research data included observations, field notes, video recordings, interviews and classroom materials. All collected data were analyzed through the Nvivo9 qualitative research software. Results have shown that CHAT is a promising field for Science Education in the early grades as pupils participate in meaningful cultural activities and receive guidance for improving or appropriating actions. In this sense learning of scientific concepts has been proved a creative component of methods, interactions and social practices. All in all, CHAT offers the potential to participate in meaningful cultural activities and receive scaffolding for improving of actions towards an inspiring object into the whole activity system.
\end{abstract}

Keywords: cultural historical activity theory (CHAT); science education; early grades; cartoon

\section{Introduction}

This paper is part of a research study which takes place in the University of Ioannina, Greece and focuses on the connection of Cultural Historical Activity Theory (CHAT) with Science Education in the early years. The research study is supported by the @ fise group of Ioannina that works on new researching lines considering CHAT as a substantial paradigm in Science teaching (Plakitsi, 2013).

\subsection{Theoretical Framework}

This study focuses on the development of a Science Education curriculum within the frame of CHAT by using cartoons as a cultural and meditative tool. It supports that education from the early grades establishes the foundations of scientific knowledge that forms individualities who consider science as a lifelong learning activity. An appropriate science teaching curriculum at all educational levels which helps understanding scientific concepts and develops scientific argumentation should make connections with society. Within the theoretical framework of CHAT, learning becomes a human activity in which theory and praxis are strongly connected and learning outcomes are obviously seen in society and culture.

Activity theory originated in the classical German philosophy (from Kant to Hegel), in the writings of Marx and Engels, and in the Russian studies in psychology of Vygotsky, Leont'ev, and Luria. The cultural- historical approach of the theory was expanded, organized and increasingly used to create contemporary research environments (Engeström, 2001). There was an increase in international interest in activity theory during the 1990s while today the theory is applied in different domains such as psychology, work research, education, in many countries worldwide (Kaptelinin \& Nardi, 2006).

The socio-cultural frame of Activity theory provides a context of human activity and links the individual to the social level (Engeström, 1999). The unit of analysis is the activity which includes the person or group who is acting 
towards an object, following certain rules and the dynamic relationships that develop within the activity system (Engeström, 1999; Barab, Evans \& Baek, 2003).

Within the CHAT frame, Science Education is established as participation in the community (Roth \& Lee, 2004) with connections to the society in its cultural and historical evolution. Subjects become engaged in science activities and they use tools in order to deal with a scientific concept. Furthermore, they interact with one another as well as with tools and means into the community of learners and work on the construction of knowledge with outcomes that are scientifically accurate (Engeström, 2005).

CHAT offers a cross-scientific field of action in which authority and expertise are put under question as they do not apply to the cultural-historical content of the theory. Furthermore, it shows ways in which authority transforms from personal to collective activity. An activity system studies both the interpersonal and intrapersonal level of actions as well as the community (Engeström, 1987; Leontiev, 1981). Within this frame, CHAT contributes to the analysis of the evolution of activity systems through historical time and to the development of collaborative activities.

In the CHAT theoretical framework, emphasis is put on the fact that the activity takes place in different levels that are not necessarily successive (Bertelsen \& Bodkaer, 2003). In fact, the activity is a system that evolves historically through time and space (historicity) and has to be considered as part of its cultural and historical frame in order to be analyzed in its parts.

Within the cultural-historical framework of CHAT, the individual and its learning experience are totally related to the social environment the individual was born. Human interactions with the environment are socially defined and contribute to the comprehension of the human mind. This aspect has connections with the basic principles that constitute an activity system. The basic principles of CHAT include the hierarchical structure of activity, object-orientedness, internalization/externalization, tool mediation, and development. These principles are interrelated and form the basic components of the theory. For example, it is necessary to define object-orientedness in order to understand the hierarchical structure of activity as well as the transformations that take place in the process of developing. These transformations are interrelated with the tools of mediation. Furthermore, the dialectic relation in the principles of internalization/externalization allows individuals act and transform their sociocultural background (Kaptelinin \& Nardi, 2006).

An innovative method of introducing scientific concepts in the early grades is comics and cartoons-animations (Bongeo, 2000; Carter, 2008) or even concept cartoons (Keogh \& Naylor, 1999). Furthermore, there is a variety of educational programming languages and multimedia tools that can be used to create projects that have an impact on pupils' education and can be a basis for teaching and learning as well as developing problem-solving strategies. Cartoons and animations have been widely used by education researchers in different domains of teaching and in an effective way since they have been designed to teach specific concepts (Madden, Chung \& Dawson 2009; Tsou, Wang \& Tzeng, 2006; Peacock, 1995). According to Heitzmann and Ellmann (1982), cartoons are a significant tool for designing educational material as they offer pupils the opportunity to develop high cognitive operations.

Keogh and Naylor (1999), support teaching and learning scientific concepts by using concept cartoons and offers an alternative method of science teaching which involves discussion, investigation and motivation for learners of all educational levels. Concept Cartoons can be used not exclusively in formal learning settings but they can bridge the gap between formal and informal learning. The impact of cartoons on teaching and learning scientific concepts is obvious (Naylor \& Keogh, 2010) as they are visual representations of concepts and involve short and ordinary dialogues with ordinary characters in a familiar situation.

Teaching by using cartoons is connected with everyday situations which make pupils lacking in confidence more likely to participate in science activities. Humor, exaggeration, symbols, emotions are all elements that provide learners with very interesting types of knowledge presented in a familiar context. Furthermore, media representations of teaching using cartoons and animations capture pupils' attention and can be very effective as they are very familiar with their everyday life. Thus, science teaching with the use of cartoons is related to ideas learners already know or have directly experienced, which makes learning concepts meaningful (Mayer, 1996).

Cartoons can support teaching become a strategy to elicit pupils' ideas, challenge their thinking and develop their understanding. Teachers can create a simulation-based intelligent learning environment for their pupils than can promote change in their professional practice.

\subsection{Rationale and Purpose}

The rationale for this study was based on the fact that Science Education must start at an early age. According to Roth, 'Science education is too important to be left alone to older children and students for it might be too late for 
creating the foundations of knowing that lead to personalities interested in science as a long endeavour', (Roth, 2011). In the early grades, scientific learning is a result of social interactions connected with exploring in authentic environments, and practicing skills connected with real life situations (Roth, Goulard \& Plakitsi, 2013). Cartoons are used as cultural tools and are connected with history of science in order to engage learners in exploring a variety of scientific concepts, in experimenting, in creative thinking and providing solutions to problems. Thus, the sociocultural aspect of Science Education will offer the potential of reaching an advanced level of scientific knowledge.

The purpose of this study was set under a CHAT perspective in which scientific knowledge is a dynamic activity system and the participants, the institutions, the methods, the tools, the objects are connected in a cultural, historical and social process. In this frame the study seeks to:

- Design and analyse Science Education activities in the CHAT framework with emphasis on the interactions that take place in the activity systems while teaching.

- Use cartoons as a mediating tool to help early grade pupils gain experience about scientific concepts such as properties of light, shadows and colors.

- Provide pupils the opportunity to obtain skills of the scientific method and life skills.

- Connect knowledge with everyday life and develop metacognitive skills.

\section{Method}

\subsection{Type of research}

Designing and organizing of this research study was based on action research which has strong connections with the socio-cultural background of Activity Theory. The sociocultural studies of Vygotsky, the development of Activity Theory through the works of Leontiev and later of Engeström as well as the view of learning as mediated participation in learning communities have connections with action research aims of social change (Edwards, 2000).

Socio-cultural research studies focus on wide-ranging explorations in the relations that develop by human action as well as the environment in which this action takes place (Wertsch \& Alvarez, 1996). Through action research moments of change in the activity systems are studied in a continuous process within the learning community. Thus, education researchers have the opportunity to design material in which the CHAT context becomes a fruitful framework to combine theory and praxis through action research projects.

Table 1: Steps of Action Research Study (Cohen, Manion \& Morrison, 2000)

\begin{tabular}{ll}
\hline Step 1 & $\begin{array}{l}\text { Necessity of new methods of teaching scientific concepts } \\
\text { Discussions and pilot research within the research community with the support of } \\
\text { the @ } 1 \text { fise group }\end{array}$ \\
Step 3 & Literature review \\
Changes and modifications of the initial proposals of the first and second step \\
Step 4 & Development of didactical scenario \\
Step 6 & Data process \\
Step 7 & Didactical intervention \\
Step 8 & Data organizing and analysis. Conclusion, future research \\
\hline
\end{tabular}

\subsection{Description of Research Design}

The methodology used in this study is based on: the framework of analysis by the view of Yrjo Engeström (2005), the cultural- historical approach by Marilyn Fleer and Marianne Hedegaard (2008, 2010) about children's development in every day practices. Emphasis is put on: developing conceptual tools to understand dialogue, multiple perspectives, and networks of interacting activity systems and introducing teaching scientific concepts by using cartoons. 


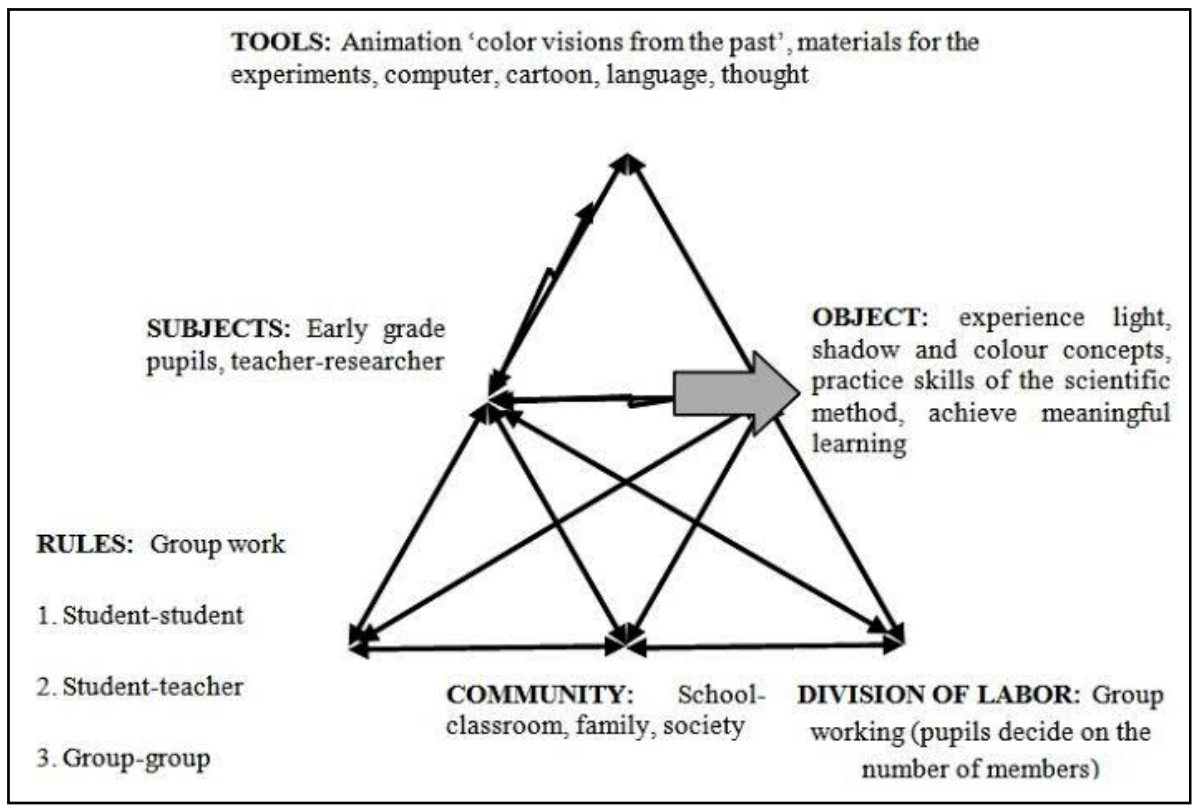

Figure 1. Activity System Model (Engeström, 1993)

This study uses elements from history of science and tends to familiarize learners with the fact that scientific concepts were developed in a certain sociocultural background of the past. It is the second part of a Science Curriculum for the early grades that was developed in order to introduce teaching scientific concepts by using cartoons. In the first part of the curriculum, a popular cartoon, Spongebob Squarepants, was used to design floating and sinking activities (Kolokouri \& Plakitsi, 2013).

The Science Curriculum was connected with the Greek National Curriculum for the early grades in which scientific learning has been put on a cultural- historical and social basis.

In the second part, a narrative about light, colors and shadows entitled 'Colors from the past was written as part of an Innovative Sciences Curriculum for the early grades. Then, the narrative was turned to a 20 minute animation about light, colors and shadows in the program scratch (http://scratch.mit.edu/) and a series of science activities about light, colors and shadows were designed. The story of the animation 'Color Visions from the Past' takes place in a town where colors are fading day by day because of the rain and almost everything is black and white. Phoebus and Iris, who live in this town, travel through time, in an unusual way, from uncle Albert's cottage to Newton's laboratory. There, they are caught while overhearing part of Newton's lecture to the scientific community and offer to work on light and color experiments. When they manage to escape and travel back to the present, they bring invaluable information to uncle Albert's lab.

The animation was divided in 5 episodes and each time pupils watched the episode and were involved in didactically transformed activities such as discussion about the episode, role playing, organizing experiments, making lists, drawing results of experiments e. t. c. All in all, pupils participated in problem solving situations and interacted with each other as well as with the teacher. The didactic strategies that were used followed the basic principles of CHAT (group work, use of instrumental and conceptual tools, interactions between subjects, mediation between subjects and community).

Furthermore the Science Curriculum is connected with the five frames of learning in the early grades (games, routines, everyday-life situations, explorations, organized learning activities) in which all early-grade pupils should equally participate (Greek National Curriculum for Early Childhood, 2011).

In the following cluster analysis of the first part of the Science Curriculum (figure 2) the activities have been grouped together because of the characteristics they have in common regarding their connection with the five frames of learning. This was done toward the beginning phases of the analysis to help see the connections between the classroom activities and the frames of learning of the National Curriculum for Early Childhood. Thus, the activities 04, 09, 10 are connected with explorations and everyday-life situations, the activities 02, 07, 08 are organized learning activities while the activities 01,06 involve routines that pupils usually do in their school life and the activities 03,05 are games. 


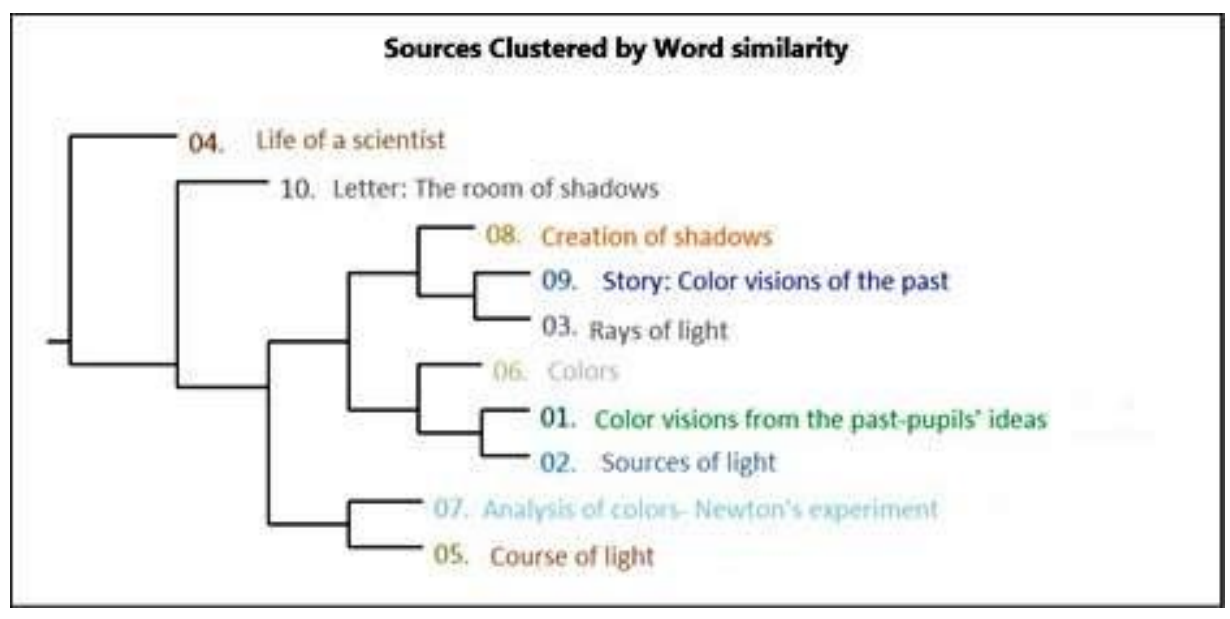

Figure 2. Nodes Clustered by Words Similarity

The didactical scenario included a series of classroom activities listed below:

- Watching the five parts of the cartoon 'Color Visions from the past': Pupils watch each part of the cartoon and discuss about the plot, the characters and their adventures.

- Pupils' ideas: pupils express their ideas about the scientific concepts of each part such as properties of light, light sources, colors, shadows.

- Classroom-laboratory: pupils decide on which part of the classroom they will transform to a laboratory. There, they deal with the scientific concepts and organize the experiments.

- Experiments: pupils conduct experiments such as analysis of colors with prisms and cds, formation of rays of light with torches, the course of light, formation of shadows, multiple shadows e. t. c.

- Drawings: pupils make drawings connected to the cartoon as well as to the results of their experiments.

- Games

- Dealing with cognitive obstacles

- Discussions: pupils discuss about the knowledge they have obtained so far as well as how to deal with new elements that come up in the course of the activities.

Table 2. Steps in the Methodology of the Curriculum

\begin{tabular}{ll}
\hline Steps & Activities \\
\hline Step 1 & Use of CHAT as a theoretical framework to design and analyze science activities for the early grades \\
Step 2 & Use of cartoons as method of introducing scientific concepts within the CHAT frame \\
Step 3 & Review of scientific curricula for the early grades at a local and international level \\
Step 4 & Use of a popular cartoon character (Sponge Bob Square Pants) to teach about floating and sinking \\
& concepts \\
Step 5 & Writing of a story about colors connected with History of Science \\
& Creation of a cartoon-animation in the scratch program based on the narration (http://scratch.mit.edu/) \\
Step 6 & Development of a science-activities series about light, colors and shadows for the school classroom \\
Step 7 & Application of the programme in the school classroom \\
Step 8 & Process of data analysis and results. \\
& Total evaluation of the programme \\
\hline
\end{tabular}




\subsection{Data collection}

The Science Curriculum was implemented in autumn 2012 in 4 pre-primary school classrooms of 25 pupils each. Research data were collected by observations, field notes, video recordings, interviews and classroom materials. All collected data were analyzed through the creation of different projects in the Nvivo9 research software (http://www.qsrinternational.com/). The process of data analysis was inspired by action research studies as well as the qualitative research method proposed by Roth (2005).

Table 3. Sample of Data

\begin{tabular}{ccccc}
\hline Schools of Ioannina & Number of pupils & Boys & Girls & Teachers of the classroom \\
\hline 1st & 25 & 14 & 11 & 1 \\
2nd & 20 & 8 & 12 & 1 \\
2d & 23 & 13 & 10 & 1 \\
4th & 25 & 12 & 13 & 2 \\
\hline Total & 93 & 47 & 46 & 5 \\
\hline
\end{tabular}

\section{Results}

The Nvivo 9 QDA (Qualitative Data Analysis) research software was used in this study to code and analyze all collected data. Nvivo in different versions is widely used by researchers, evaluators, policy advisers, social workers, educators, and students who are involved in qualitative types of research. It enables researchers to collect, organize and analyze content from interviews, focus group discussions, audio, social media, videos and webpages. In this study Nvivo 9 software was used to classify, sort and arrange the collected data and examine the relationships as well as combine analysis with the theoretical framework of CHAT. Data were organized in:

- Sources: research materials such as documents and videos

- Nodes: categories created and organized for themes or cases

- Classifications: description of sources, nodes and their relations

- Collections: specific groups of sources, memos, folders inside the project

- Queries: text Search queries, word Frequency queries, coding queries

- Reports: about the course of analysis and information about the project

- Models: to map out ideas or to explore and present the connections in your data

Data analysis has shown so far that CHAT is a promising field for Science Education in the early grades as pupils participate in meaningful cultural activities and receive guidance for improving or appropriating actions. During the implementation of the curriculum, pupils developed interpersonal skills of communication as well as critical thinking, problem solving and argumentation skills. Pupils played multiple roles and took actions within the learning community. They organized their learning in class and used new tools in order to conduct the experiments. They interacted within the group and with the teacher, who plays the role of a mediator and they define the rules in their work. They combined prior knowledge and experience with new tools and described scientific concepts providing examples of their logical thinking and their everyday life. In this sense learning of scientific concepts has been proved a creative component of methods, thinking, interactions and social practices.

Interactions while making hypotheses increased pupils' participation in order to reach the desired outcome, to learn about light and its properties. Pupils became familiar with some episodes in the history of science and used elements from these to organize their own scientific work and progress. Furthermore, pupils described scientific concepts providing examples of their logical thinking and connected them with everyday life as the following examples from pupils' dialogues show: '- there is light in the sun, -there is light in the electricity poles that bring light to our homes, -my dad teaches physics and he told me that there are generators that produce electricity'.

In the illustrations below (Illustrations 1, 2, 3, 4) we can see drawings of pupils that were collected during the didactical intervention of the programme in which pupils depict the results of their experiments or even their ideas of the life of scientists. With the aid of the cartoon characters pupils organized experiments about light and colors and tried to follow the way Newton presented his discoveries to the scientific society. The role of the teacher was that of a mediator and a facilitator. 


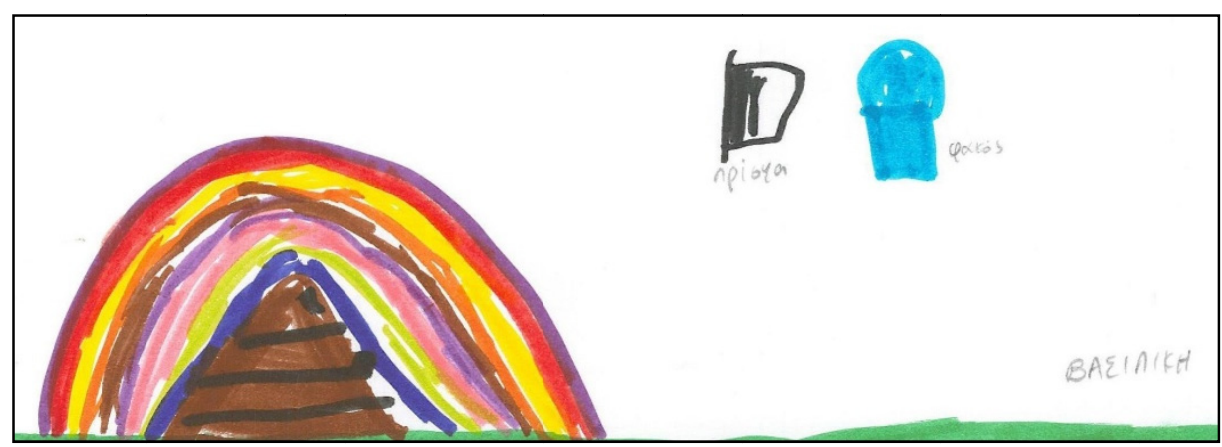

Illustration 1. Newton's Experiment on Colors

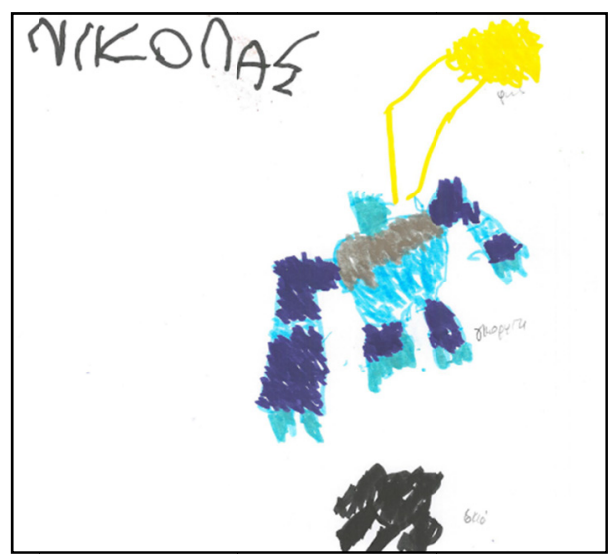

Illustration 2. Creation of Shadows
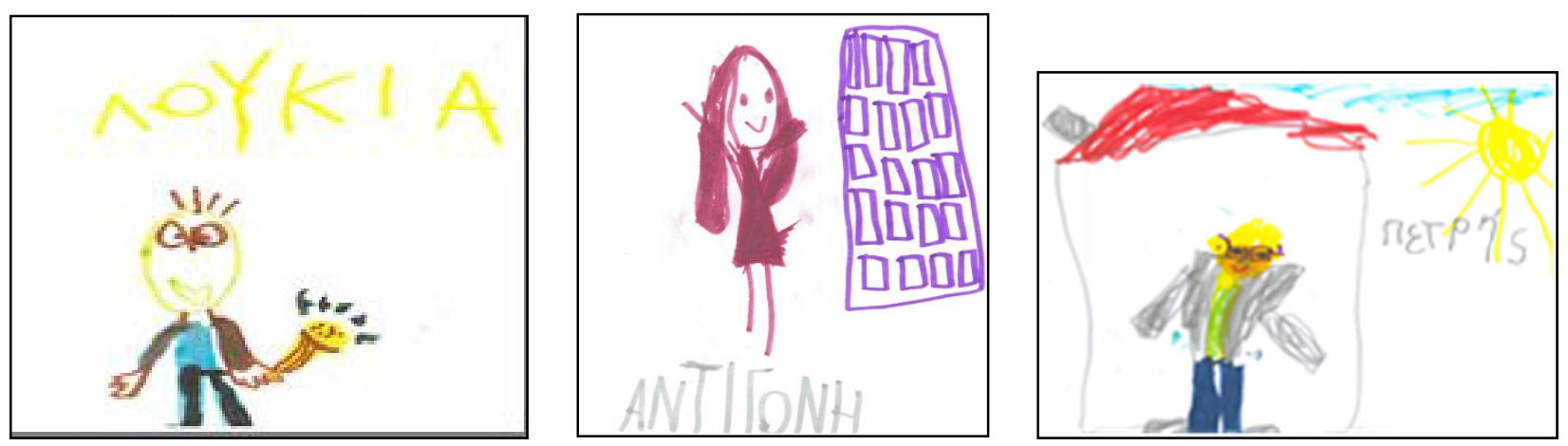

Illustrations 3, 4, 5. Images of Scientists

In the word frequency dialogue below (Figure 3) we can see the most frequently words used while analyzing. The words 'interactions, pupils, group, communication, hypotheses, experiments, object' are of high importance as they show the course of action taken within the activity system in order to reach the object. Thus, pupils interact within the learning community and use the scientific method in order to approach the scientific concepts.

The figure below (figure 4) is illustrating the skills of the scientific method that pupils practiced during the implementation of the science curriculum. Using cartoon characters and role-playing pupils visualized time and space relations, made hypotheses in order to approach the scientific concepts. Furthermore, they organized experiments, made predictions and even tested them at the end. Communication was the most prevalent and was combined with almost every other skill. Communication is an essential skill for early-grade pupils as they use a variety of means to describe an action, object or event. During the implementation of the curriculum communication took many forms and was present at every moment of action. Pupils communicated in order to share their 
observations or predictions and tried to make themselves understood in an effective way. Furthermore, dealing with scientific concepts with the aid of cartoon characters and role-playing involved forms of communication which contributed to better understanding of science, connecting with prior knowledge and building a strong interactive network in order to achieve meaningful learning of the scientific content.

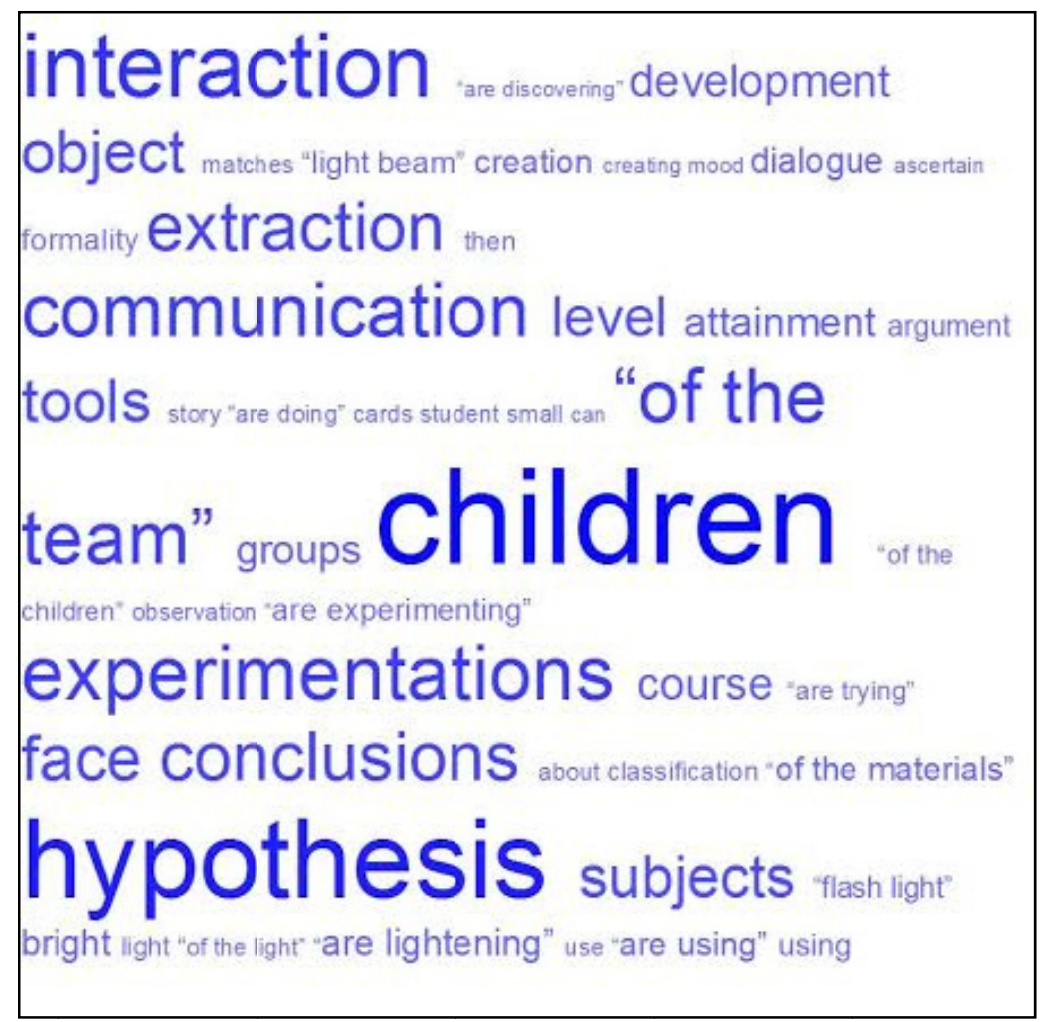

Figure 3. Word Frequency Dialogue

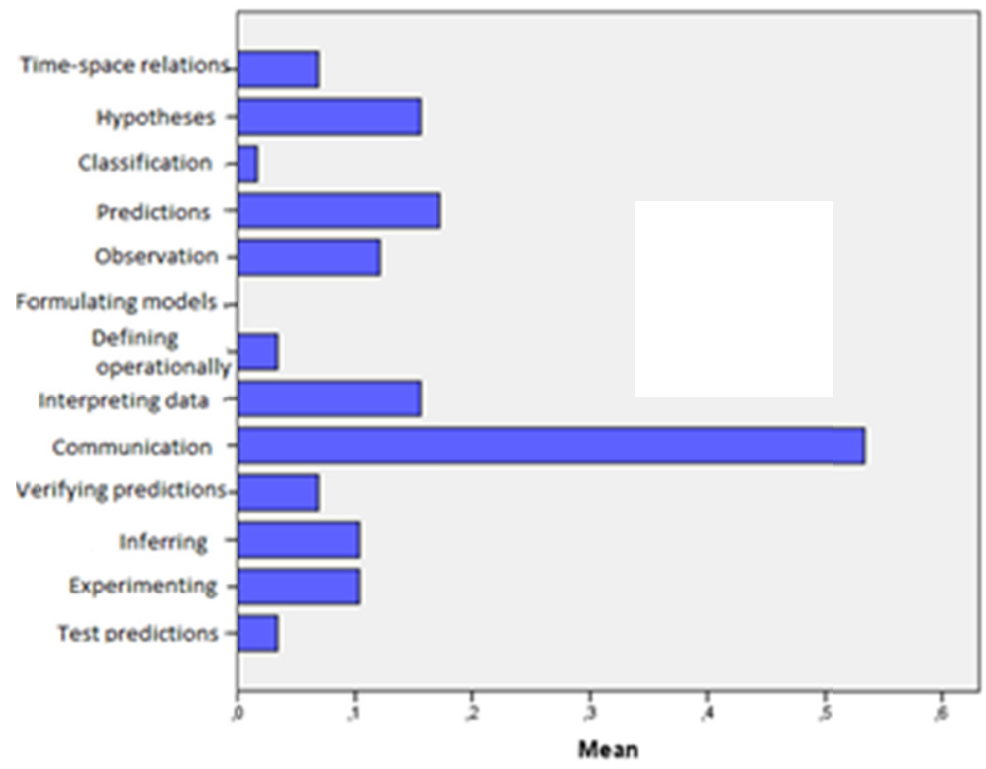

Figure 4. Skills of the Scientific Method 
The tree text search for the word 'interactions' illustrates the multiple interactions that take place in the school classroom (student-student, student-teacher, group-group, group-teacher, teacher-group). Pupils are on continuous interactions with one another as well as with the teacher through collective work with the aim of achieving scientific knowledge. They combine prior knowledge with the present and use prior experience while moving from one activity to the other. As a result, pupils come to understand the scientific concepts not as an individual, isolated phenomenon but as part of the cultural-historical and social background. Conducting research under the prism of CHAT reveals the pupil's perspective in relation to the activity as well as to the socio-cultural situation in each school. The motives, personal interests, aims of pupils seem to be in dynamic interaction with all the people they work with.
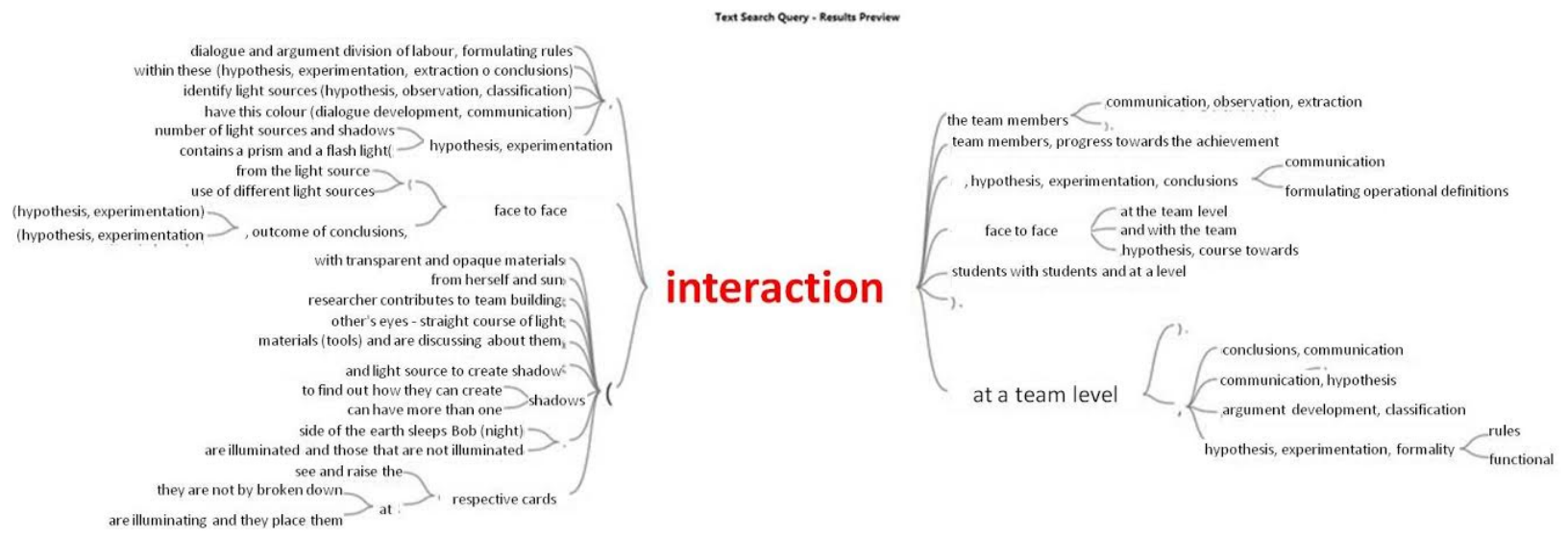

Figure 5. Tree Text Search for the Word 'Interactions'

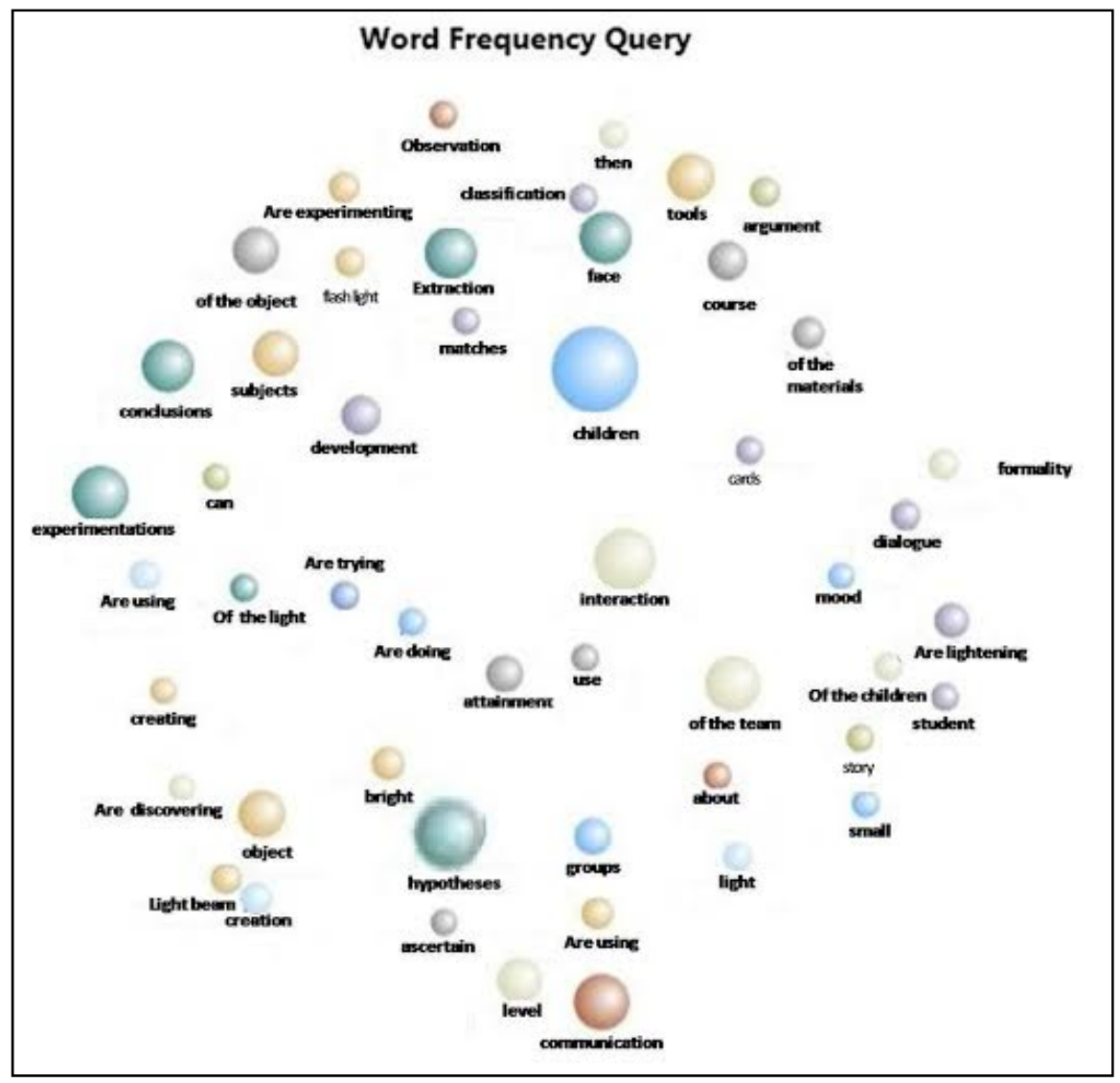

Figure 6. 3D Cluster Analysis Diagram 
In this three dimensional diagram (Figure 6) similar items are clustered together and form groups of the most important concepts of the didactical intervention such as types of interactions (group, course, dialogue) or skills of the scientific method that pupils follow (children, hypotheses classifications, conclusions). The connections in these clusters show the development of the essential skills for early-grade pupils while they participate in an action, object or event. During the implementation of the curriculum skills of the scientific method were present at almost every moment of action. Pupils communicated in order to share their observations or predictions made hypotheses and tried to predict before the experiments and drew conclusions. Furthermore, pupils tried to make themselves clear and effective and interact with the other person to make them understand their point of view.

In the following word frequency query (Figure 7) conceptual relations that concern the learning procedure are illustrated. Pupils realize that scientific concepts can be developed in different institutional settings of the present and the past, as a result of collaborative action, critical thinking, problem solving and argumentation. In this sense, internal activities, such as pupils' understanding of the scientific concepts are shaped with external activities and they both unify to form knowledge structures.

Word Frequency Query

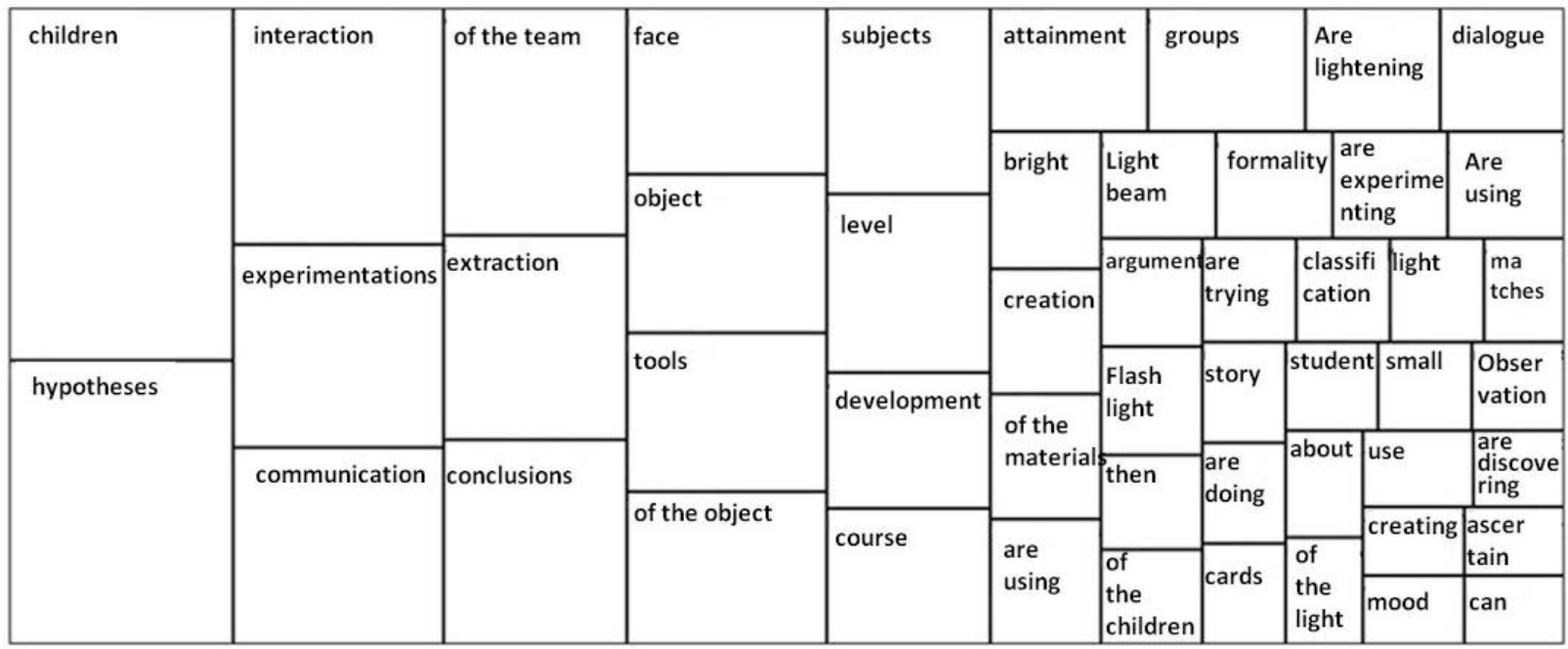

Figure 7. Conceptual Relations

In the activity system below (Figure 8) teacher and pupils use tools which are on the top and collaborate in order to reach the object. Each learning task is a system that makes progress through space and time (historicity).

Within an activity system there are terms which represent higher order functions arising from the mutual relations among components or nodes of the subtriangles (production, consumption, distribution, exchange).

The production sub-triangle contains consumption elements at the same time which in fact generates the whole system. This co-existence of production and consumption at the same time create a need state for new production.

According to Engeström (1987) there is a need state which through interactions causes contradictions-changes within the activity system. These contradictions lead to the expansion and evolution of the activity system.

In this frame, pupils explore about learning concepts and make connections with their needs and everyday life; the teacher does not just teach concepts but takes an intermediary role that allows him better understanding of the pupil dealing with scientific concepts.

Learning is expanded in the wider community which includes family and social organizations all of which act in various ways within an activity system. Contradictions within the activity system lead to changes that affect the object in multiple ways. 


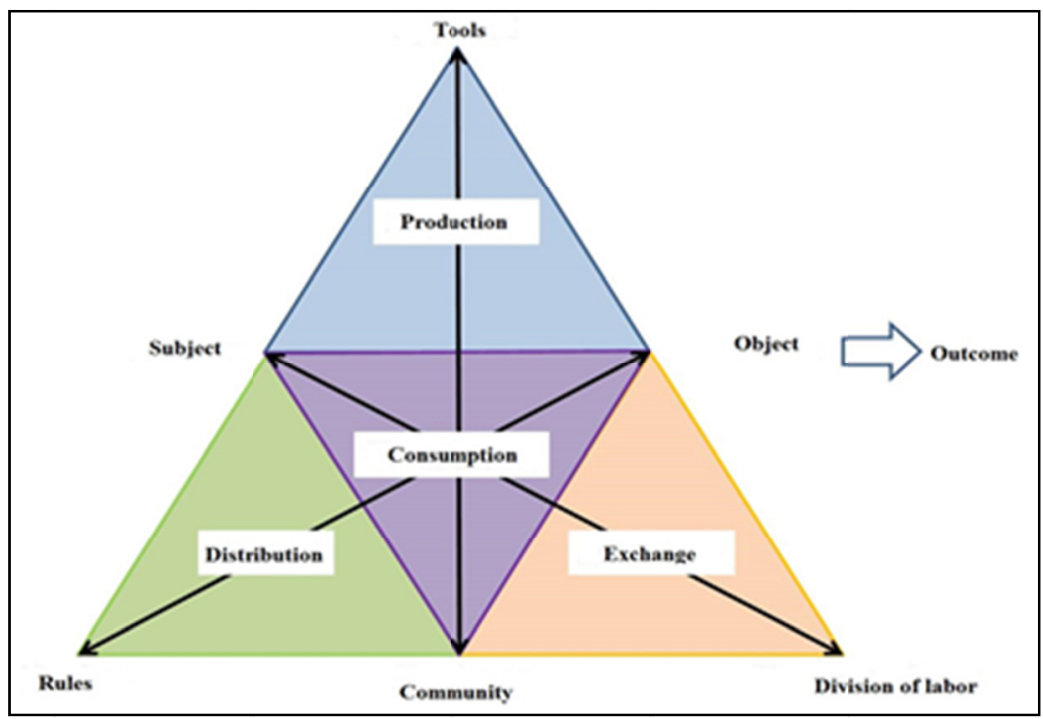

Figure 8. Activity System Model (Engeström, 1987)

\section{Discussion}

The theoretical framework of CHAT offers an alternative way of approaching Science Education from the early grades as it supports science activities based on socio-cultural approaches. Results of using CHAT to design and analyze science education activities seem promising. Cultural studies of Science Education seem to be a new potential to make science education a matter for all citizens, or in other words an alternative way to achieve scientific literacy. Learning in a CHAT frame helps pupils organize their scientific work and progress. They develop communication and life skills which enable them deal with scientific concepts in an effective way.

Cartoons and animations as a form of art influence the human nature and reinforce the learning process by using symbols and pictures. Humour and exaggeration, familiar characters and objects from everyday life, seem to have an appeal to early grade pupils. Furthermore, they provide the opportunity to make changes in the professional practice of teachers as it is quite simple to use them in the classroom and they immediately raise pupils' interest. Dealing with scientific concepts with the aid of cartoon characters in this study involved forms of communication which contributed to better understanding of science, connecting with prior knowledge and building a strong interactive network in order to achieve meaningful learning of the scientific content. The contribution of this research study in Science Education in the early grades focuses on the fact that it provides a science curriculum based on CHAT that can become a substantial paradigm in science teaching. In this sense it can support the development of a variety of thematic unions in science teaching and furthermore it can contribute to teachers' training.

CHAT opens up new fields of discussion concerning human interaction with technology and potentially can be fruitful in encouraging participation in conversations about global concerns. The modern learning environments constitute multicultural learning communities, in which learners are asked to work effectively within different groups - learning communities. This process emphasizes the importance of the cultural behaviour of tools, being supported by the analysis of human activities. Taking this into account, learning is an on-going process which is affected by societal conditions while aims and goals can be modified according to current circumstances and pupils' interest. Under the prism of CHAT pupils participate in meaningful cultural activities and receive scaffolding for improving of actions towards an inspiring object into the whole activity system. In this regard, learning processes are based on the multiple interactions that take place in the community and support the development of cultural and mediative tools which help students learn combining their personal experience and knowledge with the interactions of the group.

\section{References}

Barab, S. A., Evans, M., \& Baek, E.-O. (2003). Activity theory as a lens for charactering the participatory unit. In: D. Jonassen (Ed.), International Handbook on Communication Technologies V2 (pp. 199-214). Mahwah, NJ: Lawrence Erlbaum Associates. 
Bertelsen, O., \& Bodker, S. (2003). Activity Theory. In J. Carroll (ed.), HCI Models, Theories and Frameworks: Toward a Multidisciplinary Science (pp. 291-324). Amsterdam: Morgan Kaufmann. http://dx.doi.org/10.1016/B978-155860808-5/50011-3

Bongco, M. (2000). Reading Comics: Language, Culture and the Concept of the Superhero in Comic Books. New York: Garland Publishing Inc.

Carter, J. (2008). Dora the Explorer: Preschool Geographic Educator. Journal of Geography, 107(3), 77-86. http://dx.doi.org/10.1080/00221340802419377

Cohen, L., Manion, L., \& Morrison, K. (2000). Research Methods in Education (5th Edition). London: Routledge Falmer. http://dx.doi.org/10.4324/9780203224342

Edwards, A. (2000). Looking at Action Research through the lenses of Sociocultural Psychology and Activity Theory. Educational Action Research, 8(1), 195-204. http://dx.doi.org/10.1080/09650790000200104

Ellman, N. (1982). Comic in the classroom. In J. L. Thomas (Ed.), Cartoon and comic in the classroom: A reference for teachers and librarians (pp. 29-32). Littleton, CO: Libraries Unlimited.

Engeström, Y. (1987). Learning by expanding. Helsinki: Orienta - Konsultit.

Engeström, Y. (1999). Activity theory and individual and social transformation. In Y. Engeström, R. Miettinen \& R-L. Punamääki (Eds.), Perspectives on Activity Theory. Cambridge: Cambridge University Press.

Engeström, Y. (2005). Developmental work research: Expanding activity theory in practice. Berlin: Lehmanns Media.

Engeström, Y., (2001). Expansive Learning at Work: toward an activity theoretical reconceptualization. Journal of Education and Work, 14(1), 133-156. http://dx.doi.org/10.1080/13639080020028747

Fleer, M., \& Hedegaard, M. (2010). Children's development as participation in everyday practices across different institutions. Mind, Culture and Activity, 17(2), 149-168. http://dx.doi.org/10.1080/10749030903222760

Hedegaard, M., \& Fleer, M. (2008). Studying Children: A Cultural-Historical Approach. London: Open University Press.

Heitzmann, W. R. ( 1982). The political cartoon as a teaching device. In J. L. Thomas (Ed.), Cartoon and comic in the classroom: A reference for teachers and librarians (pp. 50-62). Littleton, CO: Libraries Unlimited.

Kaptelinin, V., \& Nardi, B. (2006). Acting with technology: Activity theory and interaction design. Cambridge: MIT Press.

Keogh, B., \& Naylor, S. (1999). Concept Cartoons, teaching and learning in science: An initial evaluation. Public understanding of Science, 8, 1-18. http://dx.doi.org/10.1088/0963-6625/8/1/001

Kolokouri E., \& Plakitsi K. (2013). A Cultural Historical Scene of Natural Sciences for early learners: A Chat Scene. In K. Plakitsi (Ed.). Cultural perspectives in science education: Research dialogs. Activity theory in formal and informal education (pp. 197-228). The Netherlands: Sense Publishers. http://dx.doi.org/10.1007/978-94-6091-317-4_8

Leontiev, A. N. (1981). Problems of the development of the mind. Moscow: Progress.

Madden, M., Chung, P.W.H., \& Dawson, C.W. (2009). Cartoons beyond clipart: A computer tool for storyboarding and storywriting. Computers \& Education, 52(1), 188-200. http://dx.doi.org/10.1016/j.compedu.2008.07.009

Mayer, R. (1996). Learners as information processors: Legacies and limitations of educational psychology's second metaphor. Education Psychology, 31, 151-161. http://dx.doi.org/10.1080/00461520.1996.9653263

Naylor, S., \& Keogh, B. (2010). Concept Cartoons in Science Education (2nd Ed.). Sandbach: Millgate House.

Peacock, A. (1995). An agenda for research on text material in primary science for second language learners of English in developing countries. Journal of Multilingual and Multicultural Development, 16, 389-401. http://dx.doi.org/10.1080/01434632.1995.9994614

Plakitsi, K. (2013). Activity Theory in Formal and Informal Science Education. The Netherlands: Sense Publishers. $\mathrm{http}: / / \mathrm{dx}$. doi.org/10.1007/978-94-6091-317-4

Roth, W. M., \& Lee, S. (2004). Science education as/for participation in the community. Science Education, 88 , 263-291. http://dx.doi.org/10.1002/sce.10113 
Roth, W. M. (2005). Doing Qualitative Research. Canada: Sense Publishers.

Roth, W.-M. (2011). Science in/for early childhood: More than lip service. In K. Plakitsi (Ed.), Sociocultural and Sociocognitive Approaches in the Didactics of Natural Sciences in Early Childhood. Athens: Patakis.

Roth, W.-M., Goulart, M. I. M., \& Plakitsi, K. (2013). Science during early childhood: A Cultural-Historical Perspective. Dordrecht, The Netherlands: Springer. http://dx.doi.org/10.1007/978-94-007-5186-6

Tsou, W., Wang, W., \& Tzeng, Y. (2006). Applying a multimedia storytelling website in foreign language learning. Computer \& Education, 47, 17-28. http://dx.doi.org/10.1016/j.compedu.2004.08.013

Wertsch, J., del Rio, P., \& Alvarez, A. (1996). Sociocultural studies; history, action and mediation. In J. Wertsch, J., P. del Rio \& A. Alvarez (Eds.), Sociocultural Studies of Mind. Cambridge: Cambridge University Press. 